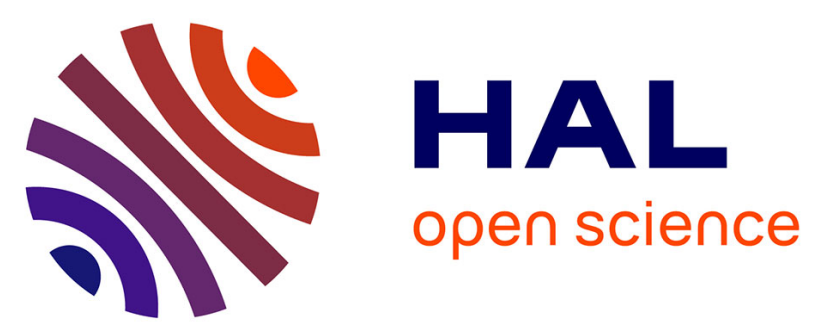

\title{
Analysis of the thermomechanical response of granular materials by infrared thermography
}

P. Jongchansitto, X. Balandraud, I. Preechawuttipong, Jean-Benoit Le Cam, P. Garnier

\section{- To cite this version:}

P. Jongchansitto, X. Balandraud, I. Preechawuttipong, Jean-Benoit Le Cam, P. Garnier. Analysis of the thermomechanical response of granular materials by infrared thermography. SEM Annual Conference and Exposition on Experimental and Applied Mechanics, 2018, Jun 2018, Greenville, United States. pp.7-11, 10.1007/978-3-319-95074-7_2 . hal-02161141

\section{HAL Id: hal-02161141}

\section{https://hal-univ-rennes1.archives-ouvertes.fr/hal-02161141}

Submitted on 10 May 2020

HAL is a multi-disciplinary open access archive for the deposit and dissemination of scientific research documents, whether they are published or not. The documents may come from teaching and research institutions in France or abroad, or from public or private research centers.
L'archive ouverte pluridisciplinaire HAL, est destinée au dépôt et à la diffusion de documents scientifiques de niveau recherche, publiés ou non, émanant des établissements d'enseignement et de recherche français ou étrangers, des laboratoires publics ou privés. 


\title{
Analysis of the Thermomechanical Response of Granular Materials by Infrared Thermography
}

\author{
Pawarut Jongchansitto, Xavier Balandraud, Itthichai Preechawuttipong, Jean-Benoît Le Cam, and Pierre Garnier
}

\begin{abstract}
Granular materials are defined as a collection of solid particles whose macroscopic mechanical behavior is governed by the interaction forces between the particles. Full-field experimental data on these materials remain few compared to numerical results, even though a wide literature deals with optical imaging (combined with digital image correlation) and photoelasticimetry (to measure shear stresses in particles made of birefringent materials). We applied infrared thermography to analyze two-dimensional granular media composed of cylinders and subjected to confined compression. We analyzed the calorific signature of the contact forces, especially by revealing mechanical dissipation in the interparticle friction zones. Moreover, two constitutive materials featuring entropic and isentropic elasticity were employed to compare distinct types of thermoelastic couplings. Couplings and mechanical dissipation were separately identified at two observation scales. The perspective of this work is the experimental analysis of soft granular media.
\end{abstract}

Keywords Granular material · Infrared thermography · Thermoelastic coupling · Friction · Entropic coupling

\subsection{Introduction}

Granular materials are omnipresent in our daily life as well as in many industrial fields. They are defined as a collection of solid particles whose macroscopic mechanical behavior is governed by the contact forces between the particles. They generally consist of grains with wide distributions in terms of size, shape and base material. Their mechanical behavior strongly differs from that of continuum solids, liquids, and gases [1]. Numerical simulation has been carried out to investigate the influence of parameters such as the particle shape, density, polydispersity, particle elasticity, friction, etc. [2]. Several experimental techniques are also available. For measurements in the bulk, let us cite X-ray tomography [3, 4], flash X-ray shadowgraphy [5], magnetic resonance imaging [6], radar-based sensing [7] and positron emission particle tracking [8]. For two-dimensional (2D) measurements, particle image velocimetry and digital image correlation were widely employed [911]. For stress measurement in the particles, photoelasticimetry is a full-field experimental technique providing the shear stresses in particles made of birefringent materials [12-16]. In the present study, we employed infrared (IR) thermography to reveal the calorific signature of the contact forces, especially in the interparticle friction zones. Moreover, two base materials were employed to compare two types of thermoelastic coupling: isentropic coupling (typical of metallic materials and polymers below their glass transition temperature) and entropic coupling (typical of rubber-like materials).

P. Jongchansitto $\cdot$ I. Preechawuttipong

Chiang Mai University, Faculty of Engineering, Department of Mechanical Engineering, Muang District, Chiang Mai, Thailand

X. Balandraud $(\triangle)$

Université Clermont Auvergne, CNRS, SIGMA Clermont, Institut Pascal, Clermont-Ferrand, France

e-mail: xavier.balandraud@sigma-clermont.fr

J.-B. Le Cam

Univ Rennes, CNRS, IPR (Institute de Physique de Rennes) - UMR 6251, Rennes, France

LC-DRIME, Joint Research Laboratory, Cooper Standard - Institut de Physique UMR 6251, Rennes Cedex, France

P. Garnier

PCM Technologies S.A.S., Rue René Moineau, Champtocé-sur-Loire, France 


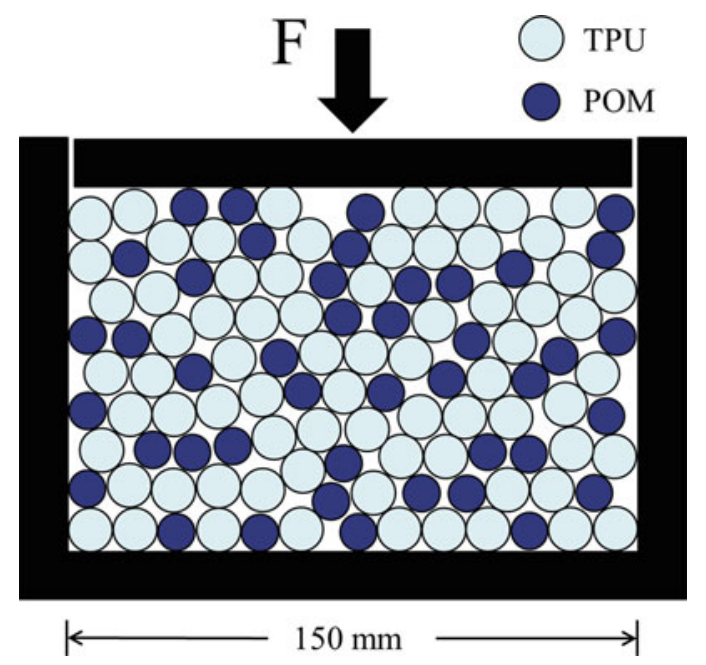

\subsection{Methodology}

The experimental configuration is presented in Fig. 2.1. Cylinders made of two types of materials were employed: thermoplastic polyurethane (TPU) and polyoxymethylene (POM). These materials differ in terms of stiffness and thermoelastic coupling. TPU is much softer than POM (ratio of about 700 in tension). TPU is governed by entropic thermoelastic coupling $[17,18]$ while POM is governed by isentropic thermoelastic coupling [19-21] at ambient temperature and within the range of mechanical loadings applied in the study. TPU cylinders were molded by PCM Technologies S.A.S. (France). See Refs. [19-21] for the properties of POM cylinders. POM cylinders were $10.5 \mathrm{~mm}$ in diameter. TPU cylinders were $12.0 \mathrm{~mm}$ in diameter. All cylinders were $60 \mathrm{~mm}$ in length. The surface of each cylinder was painted in a matte black color to homogenize and maximize the thermal emissivity.

A cyclic mechanical loading was applied to the top of the granular sample using a MTS $\pm 15 \mathrm{kN}$ uniaxial testing machine: force-controlled sinusoidal signal, frequency of $0.5 \mathrm{~Hz}$, force ratio of 0.1 , maximum compression force of $-10 \mathrm{kN}$. Ambient temperature was equal to $28^{\circ} \mathrm{C}$. A Cedip Jade III-MWIR camera was employed to capture the temperature fields on the surface of the cylinders at an acquisition frequency of $150 \mathrm{~Hz}$.

\subsection{Global Analysis}

In order to reveal irreversible phenomena occurring during the cyclic loading, we assume that the heat produced by the thermoelastic response is equal to zero over a mechanical cycle (or an integer number of cycles). The heat produced by mechanical irreversibility is always positive. The corresponding heat power density is usually named mechanical dissipation or intrinsic dissipation [22-24]. For granular materials, mechanical dissipation can be due to friction at the contacts between particles. It can be also due to the stresses inside the particles, in particular in the stress concentration zones. Figure 2.2 shows a map of temperature differences for three mechanical cycles. It can be observed that the values are close to zero except at some contacts between particles. In particular, strong thermal activity is observed along some lines inclined with respect to the loading direction. It can be checked that the higher the number of mechanical cycles considered, the higher the temperature differences due to irreversible phenomena.

In order to reveal thermoelastic couplings in the material's response during the cyclic loading, we have considered a halfcycle. The heat due to thermoelastic couplings for loading and unloading are indeed equal but with opposite signs. Figure 2.3 shows a map of temperature differences for a compression stage. It can be noted that the values are greater than those obtained in Fig. 2.2 corresponding to three entire cycles. This shows that that the amplitude of the thermoelastic effects is much greater than the thermal signature of the irreversible phenomena. It can also be observed in Fig. 2.3 that heating is not visualized only at the contacts: it is distributed inside the particles. Hotter particles are mainly made of TPU. The entropic coupling is indeed stronger than the isentropic coupling. Next section provides information at a better spatial resolution. 


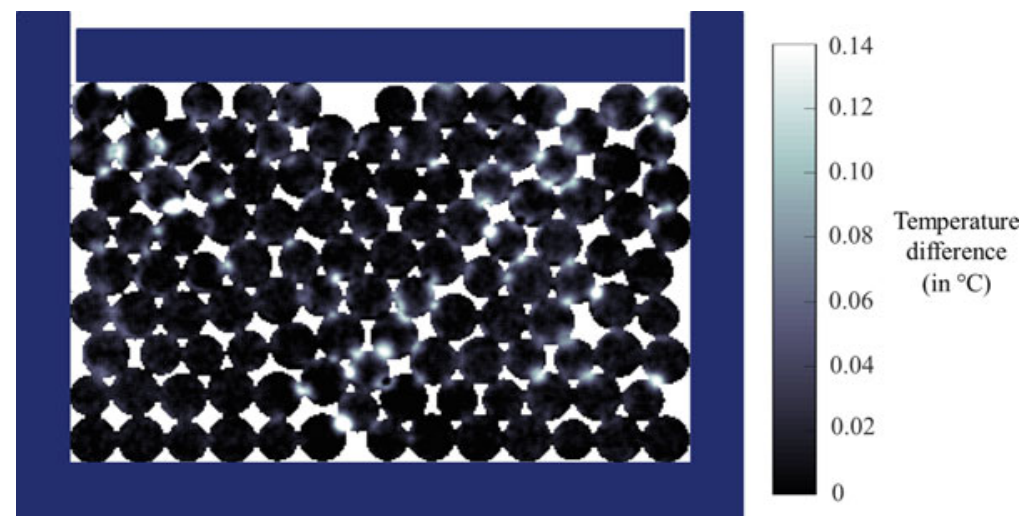

Fig. 2.2 Map of temperature differences for three mechanical cycles, revealing mechanical dissipation

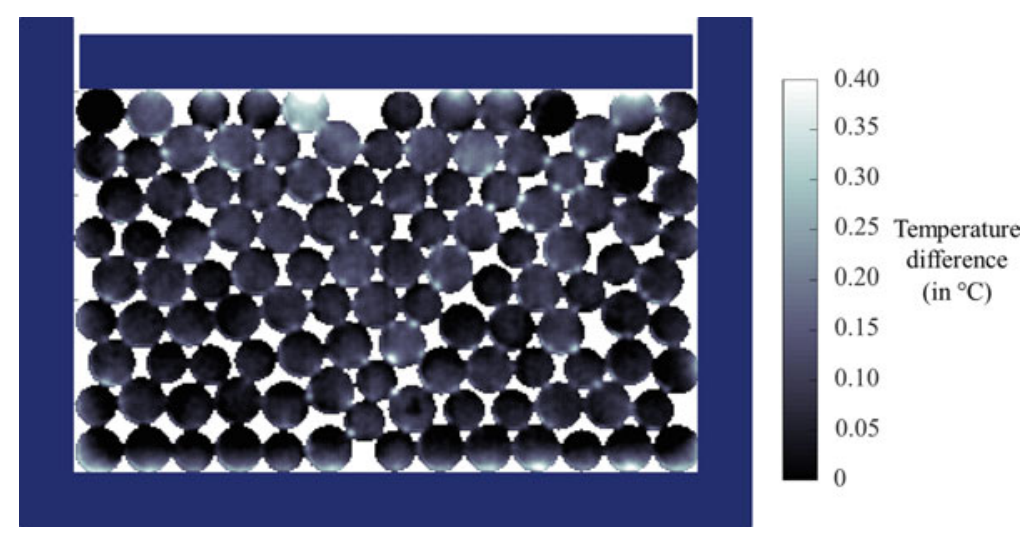

Fig. 2.3 Map of temperature differences for a half-cycle, revealing thermoelastic couplings

\subsection{Local Analysis}

The IR camera was then placed closer to the granular sample to obtain a better spatial resolution in a specific zone of the granular assembly. Similarly to the global analysis, the map of temperature differences for three mechanical cycles is presented in Fig. 2.4 to reveal mechanical dissipation. Hot zones are observed on both sides of the contact zones. This can be explained by the diffusion of the heat produced by the friction [25]. Heterogeneity in the intensity of the irreversible thermal response is clearly evidenced.

Similarly to the global analysis, the map of temperature differences for a half-cycle is presented in Fig. 2.5 to reveal thermoelastic coupling effects. The thermal patterns differ from those observed in Fig. 2.4 corresponding to irreversible phenomena. Indeed, the thermoelastic response depends on the type of material (POM or TPU) and on the local stress state, whereas the mechanical dissipation depends on the friction intensity at the contact. For example, it is possible to have a strong stress concentration (leading to strong thermoelastic effect) accompanied by low friction depending on the ratio between normal and transverse contact forces.

\subsection{Conclusion}

IR thermography is in principle applicable to any type of solid material to perform a thermomechanical analysis. However, the application to granular assemblies is difficult. The present study provides arguments for choosing constitutive materials for such analyses. It can be claimed that entropic elastic matters are excellent candidates as analogical materials for the analysis of granular media by IR thermography. Rubber-like entropic particles (such as TPU) provide strong thermoelastic responses that could be used to identify the contact force network. In addition, thermoelastic couplings and mechanical dissipation due to interparticle friction can be separately revealed. IR thermography thus provides two routes to analyze 


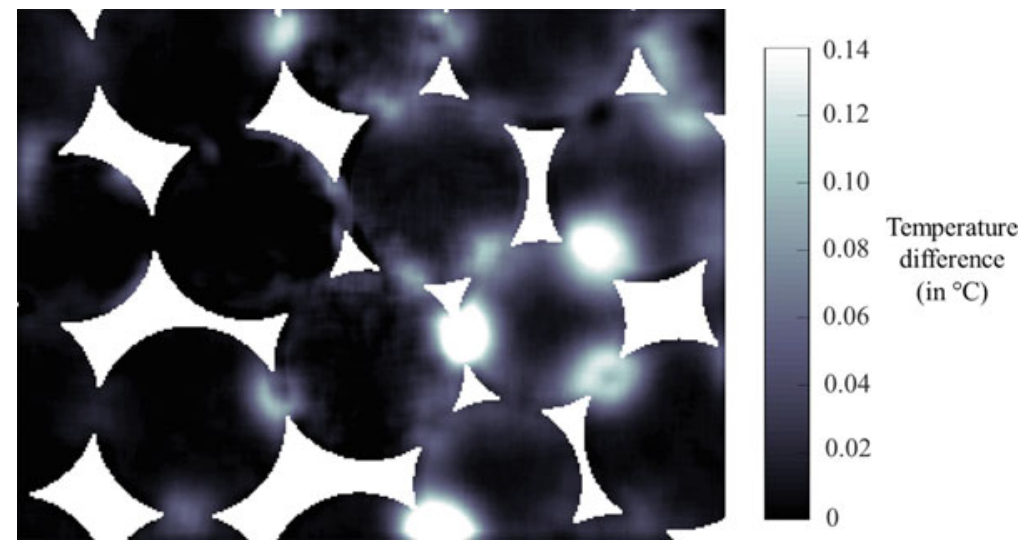

Fig. 2.4 Local analysis: map of temperature differences for three mechanical cycles, revealing mechanical dissipation

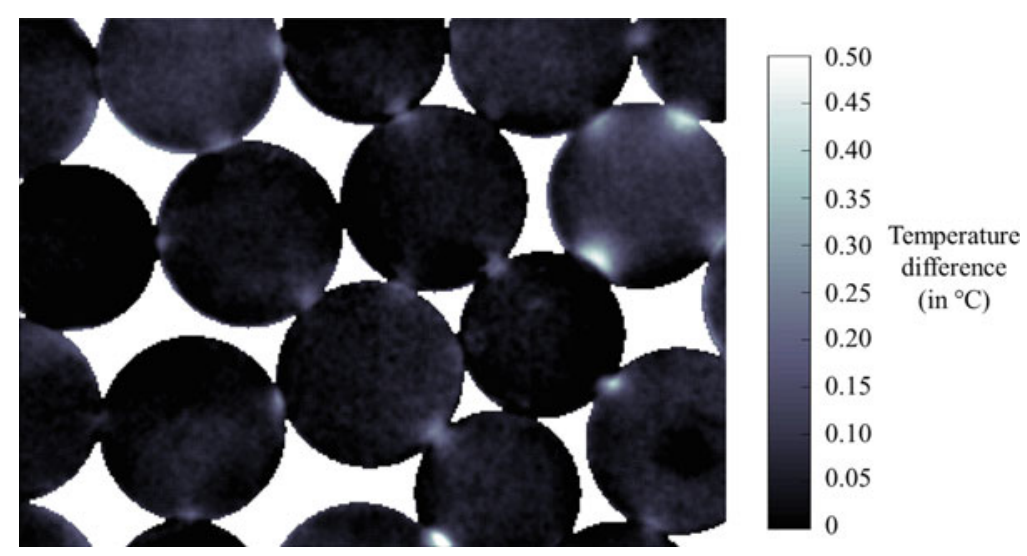

Fig. 2.5 Local analysis: map of temperature differences for a half-cycle, revealing thermoelastic couplings

granular materials. Compared to previous works performed with only isentropic materials [19-21], numerous mechanical cycles and high loading frequency are not required for the processing. Only a few mechanical cycles are necessary for the analysis: a half-cycle for revealing entropic thermoelastic coupling, and one cycle minimum for revealing irreversible phenomena. More generally, the study opens prospects for the experimental analysis of "soft" granular materials.

Acknowledgements The authors gratefully acknowledge the company PCM Technologies S.A.S., Champtocé-sur-Loire, France for their support during this research. They also gratefully acknowledge the French Embassy in Thailand and Campus France for their support during this research (PHC SIAM 2018, Project 40710SE). Finally, the authors gratefully acknowledge the Ministere de l'Europe et des Affaires Etrangeres (MEAE) and the Ministere de l'Enseignement superieur, de la Recherche et de l'Innovation (MESRI) in France, as well as the office of the Higher Education Commission (OHEC) of the Ministry of Education in Thailand.

\section{References}

1. Jaeger, H.M.: Sand, jams and jets. Phys. World. 18, 34-39 (2005)

2. Radjai, F., Roux, J.N., Daouadji, A.: Modeling granular materials: century-long research across scales. J. Eng. Mech. 143, 04017002 (2017)

3. Hall, S.A., Bornert, M., Desrues, J., Pannier, Y., Lenoir, N., Viggiani, G., Besuelle, P.: Discrete and continuum analysis of localised deformation in sand using $X$-ray $\mu \mathrm{CT}$ and volumetric digital image correlation. Geotechnique. 60, 315-322 (2010)

4. Khalili, M.H., Brisard, S., Bornert, M., Aimedieu, P., Pereira, J.M., Roux, J.N.: Discrete digital projections correlation: a reconstruction-free method to quantify local kinematics in granular media by X-ray tomography. Exp. Mech. 57, 819-830 (2017)

5. Park, H., Chen, W.: Two orthogonal layers of metal medium in granular materials for 3D speckle shadowgraph by flash X-ray. Exp. Mech. 52, 1173-1177 (2012)

6. Nakagawa, M., Altobelli, S.A., Caprihan, A., Fukushima, E., Jeong, E.K.: Non-invasive measurements of granular flows by magnetic resonance imaging. Exp. Fluids. 16, 54-60 (1993) 
7. Hill, K.M., Fan, Y., Zhang, J., Van Niekerk, C., Zastrow, E., Hagness, S.C., Bernhard, J.T.: Granular segregation studies for the development of a radar-based three-dimensional sensing system. Granul. Matter. 12, 201-207 (2010)

8. Parker, D.J., Dijkstra, A.E., Martin, T.W., Seville, J.P.K.: Positron emission particle tracking studies of spherical particle motion in rotating drums. Chem. Eng. Sci. 52, 2011-2022 (1997)

9. Slominski, C., Niedostatkiewicz, M., Tejchman, J.: Application of particle image velocimetry (PIV) for deformation measurement during granular silo flow. Powder Technol. 173, 1-18 (2007)

10. Hall, S.A., Wood, D.M., Ibraim, E., Viggiani, G.: Localised deformation patterning in 2D granular materials revealed by digital image correlation. Granul. Matter. 12, 1-14 (2010)

11. Richefeu, V., Combe, G., Viggiani, G.: An experimental assessment of displacement fluctuations in a 2D granular material subjected to shear. Geotech. Lett. 2, 113-118 (2012)

12. Zhang, J., Majmudar, T.S., Sperl, M., Behringer, R.P.: Jamming for a 2D granular material. Soft Matter. 6, 2982-2991 (2010)

13. Wood, D.M., Lesniewska, D.: Stresses in granular materials. Granul. Matter. 13, 395-415 (2011)

14. Lesniewska, D., Wood, D.M.: Photoelastic and photographic study of a granular material. Geotechnique. 61, 605-611 (2011)

15. Zhang, L., Cai, S., Hu, Z., Zhang, J.: A comparison between bridges and force-chains in photoelastic disk packing. Soft Matter. 10, 109-114 (2014)

16. Mirbagheri, S.A., Ceniceros, E., Jabbarzadeh, M., McCormick, Z., Fu, H.C.: Sensitively photoelastic biocompatible gelatin spheres for investigation of locomotion in granular media. Exp. Mech. 55, 427-438 (2015)

17. Mott, P.H., Giller, C.B., Fragiadakis, D., Rosenberg, D.A., Roland, C.M.: Deformation of polyurea: where does the energy go? Polymer. 105, 227-233 (2016)

18. Lachhab, A., Robin, E., Le Cam, J.B., Mortier, F., Tirel, Y., Canevet, E.: Thermomechanical analysis of polymeric foams subjected to cyclic loading: anelasticity, self-heating and strain-induced crystallization. Polymer. 126, 19-28 (2017)

19. Chaiamarit, C., Balandraud, X., Preechawuttipong, I., Grédiac, M.: Stress network analysis of 2D non-cohesive polydisperse granular materials using infrared thermography. Exp. Mech. 39, 761-769 (2015)

20. Jongchansitto, P., Balandraud, X., Grédiac, M., Beitone, C., Preechawuttipong, I.: Using infrared thermography to study hydrostatic stress networks in granular materials. Soft Matter. 10, 8603-8607 (2014)

21. Jongchansitto, P., Preechawuttipong, I., Balandraud, X., Grédiac, M.: Numerical investigation of the influence of particle size and particle number ratios on texture and force transmission in binary granular composites. Powder Technol. 308, 324-333 (2017)

22. Halphen, B., Nguyen, Q.S.: Sur les matériaux standard généralisés. Journal de Mécanique. 14, 39-63 (1975)

23. Samaca Martinez, J.R., Le Cam, J.B., Balandraud, X., Toussaint, E., Caillard, J.: Mechanisms of deformation in crystallizable natural rubber. Part 1: thermal characterization. Polymer. 54, 2717-2726 (2013)

24. Le Cam, J.B., Samaca Martinez, J.R., Balandraud, X., Toussaint, E., Caillard, J.: Thermomechanical analysis of the singular behavior of rubber: entropic elasticity, reinforcement by fillers, strain-induced crystallization and the Mullins effect. Exp. Mech. 55, 771-782 (2015)

25. Jongchansitto, P., Balandraud, X., Preechawuttipong, I., Le Cam, J.B., Garnier, P.: Thermoelastic couplings and interparticle friction evidenced by infrared thermography in granular materials. Exp. Mech. (2018, submitted) 